\title{
Glycomic approach for potential biomarkers on prostate cancer: Profiling of N-linked glycans in human sera and pRNS cell lines
}

\author{
Maria Lorna A. de Leoz ${ }^{\mathrm{a}}$, Hyun Joo An ${ }^{\mathrm{a}}$, Scott Kronewitter ${ }^{\mathrm{a}}$, Jaehan Kim ${ }^{\mathrm{b}}$, Sean Beecroft ${ }^{\mathrm{a}}$, \\ Ruth Vinall $^{\mathrm{c}}$, Suzanne Miyamoto ${ }^{\mathrm{d}}$, Ralph de Vere White ${ }^{\mathrm{d}}$, Kit S. Lam ${ }^{\mathrm{d}}$ and Carlito Lebrilla ${ }^{\mathrm{a}, e, *}$ \\ ${ }^{a}$ Department of Chemistry, University of California Davis, Davis, CA, USA \\ ${ }^{\mathrm{b}}$ Department of Viticulture and Enology, University of California Davis, Davis, CA, USA \\ ${ }^{\mathrm{c}}$ Department of Urology, University of California Davis Medical Center, Sacramento, CA, USA \\ ${ }^{\mathrm{d}}$ Division of Hematology and Oncology, University of California Davis Medical Center, Sacramento, CA, USA \\ ${ }^{\mathrm{e}}$ Department of Biochemistry, School of Medicine, University of California Davis, Davis, CA, USA
}

\begin{abstract}
Prostate cancer is a leading cause of cancer death among men. Currently available screening test measures prostatespecific antigen (PSA) to detect prostate cancer. However, this test produces false positive values that often lead to negative biopsies. Therefore, a more reliable diagnostic tool is needed. Glycans in serum are of particular interest as around half of all proteins are glycosylated. In this study, N-linked glycans were enzymatically released by PNGase F from prostate epithelial cell lines (pRNS) expressing wild type or mutant androgen receptors and a small set of human serum samples. Released glycans were purified and partitioned into neutral and acidic components by solid phase extraction (SPE) using graphitized carbon cartridges. The SPE fractions were analyzed by matrix-assisted laser desorption/ionization Fourier transform ion cyclotron resonance mass spectrometry (MALDI FT-ICR MS). Significant changes in some high-mannose and fucosylated biantennary complex N-linked glycans were observed in the serum of prostate cancer patients.
\end{abstract}

Keywords: Biomarker, glycans, mass spectrometry, prostate cancer, serum

\section{Introduction}

Prostate cancer is the second leading cause of cancer death and the most frequently diagnosed cancer among men. In 2007, the estimated number of deaths and new cases in the US alone are 27,050 and 218,890, respectively [1]. Although the exact cause of prostate cancer is still unknown, several risk factors are associated with it, including age, race, family history, and diet [1]. Unfortunately, the common symptoms of prostate cancer are not specific to the disease and early stage may show no noticeable symptoms. Early diagnosis is important because prostate cancer may be more easily and suc-

${ }^{*}$ Corresponding author. Tel.: +1 530752 6364; Fax: +1 530752 8995; E-mail: cblebrilla@ucdavis.edu. cessfully treated when detected early. It is estimated that if the cancer is diagnosed at localized stages, $100 \%$ of men will survive longer than five years. At distant stages, however, only $33 \%$ will survive longer than five years [1,2].

Currently, the prostate specific antigen (PSA) is regarded as the best tumor marker for prostate cancer [24]. PSA is a glycoprotein that helps in the liquefaction of the semen. A PSA concentration below $4 \mathrm{ng} / \mathrm{mL}$ in the serum implies the absence of cancer, since the release of PSA in the bloodstream of healthy individuals is unlikely. However, there are instances when the membrane of the prostate epithelial cells is disrupted which leads to the disproportionate leaking of PSA into the bloodstream. Moreover, an enlargement of the prostate is known to affect PSA levels. Thus, there 
may be an increase in serum PSA levels not only in prostate cancer, but also in benign prostate diseases such as benign prostatic hyperplasia (BPH) and physical trauma of the prostate. An increase in the serum PSA levels, therefore, is indicative of pathologies of the prostate gland, but PSA may not be a specific marker for prostate cancer [4,5]. Thus, PSA oftentimes gives false positive values that may lead to unnecessary biopsies. Approximately $60-80 \%$ of PSA-driven prostate biopsies are negative [2,4]. A more alarming concern is the reported $20 \%$ incidence of false negatives in the low PSA levels, i.e. in the range of $2.5-4 \mathrm{ng} / \mathrm{mL}$ [6]. Clearly, a more sensitive and specific diagnostic tool for prostate cancer is needed.

Recently, the percent free PSA, which is the ratio of free PSA to total PSA, is being explored as a more reliable screening test for prostate cancer than PSA. This test improves sensitivity to 90-95\%, consequently reducing the number of unneeded biopsies to $15-20 \%$. Other PSA tests that are examined include PSA density, PSA velocity, percent complex PSA, and new molecular forms of PSA such as proPSA, BPSA, 'intact' PSA, PSA-A2M and PSA-API [2,4,5,7].

Other biomarkers aside from PSA have also been studied. For example, Bondar et al. have looked at $\mathrm{Zn}-\alpha 2$ glycoprotein (ZAG) as a potential biomarker for prostate cancer [8]. They quantified a unique peptide by subjecting ZAG to proteolytic cleavage followed by liquid chromatography and tandem mass spectrometry (LC-MS/MS) analysis. Another potential protein biomarker for prostate cancer is $\alpha$-methylacylcoenzyme-A racemase (AMACR) [9]. Maraldo et al. quantified AMACR from urine without sample preparation using a macrocantilever-based technique. Thus, biomarkers associated with the presence of prostate cancer have been extensively studied using electrophoresis, protein expression, tissue microarrays, macrocantilevers, tandem mass spectrometry (LC MS/MS), matrix-assisted laser desorption ionization (MALDI) and surface enhanced laser desorption ionization (SELDI)-mass spectrometry (MS) [10-13], but these potential biomarkers still need to undergo validation before acceptance in the clinical laboratory.

Changes in glycosylation have been implicated in many diseases including cancer [14-18]. Glycosylation, whether $\mathrm{N}$-linked or O-linked, is highly sensitive to the biochemical environment and is the most common post-translational modification of proteins on the cell surface and in the extracellular matrix [19-21]. The biosynthesis of oligosaccharides relies on a number of highly competitive processes, suggesting that the concentration of specific glycosyl transferases is highly variable and could yield completely different products. Because of this, monitoring changes in glycosylation may prove to be a more specific and sensitive method for biomarker discovery and disease diagnosis.

Studies have been made in our laboratory regarding O-linked glycans, i.e. glycans attached to the serine (Ser) or threonine (Thr) residue of the protein. For ovarian cancer, fifteen possible O-linked glycan markers were found in patient sera that were not found in normal sera [16,22]. We also analyzed several breast cancer tumor cell lines and patient sera for possible breast cancer "glycan signatures" [23]. In all cases, the O-linked glycans were released by $\beta$-elimination and analyzed by matrix-assisted laser desorption/ionization Fourier transform ion cyclotron resonance (MALDI FT-ICR) mass spectrometry and infrared multiphoton dissociation (IRMPD). In these studies, some glycan masses were found that were derived from N-linked glycans that could have been produced by cross-ring cleavage from the sodium borohydride treatment.

We analyzed the $\mathrm{N}$-linked glycans in prostate epithelial cells and human sera in this present study. The $\mathrm{N}$-linked glycans are of particular interest since they are more abundant in human sera than O-linked glycans [19]. In N-glycosylation, the glycan is attached to the asparagine (Asn) residue of the protein in the consensus sequence Asn-Xaa-Ser/Thr (Xaa = any amino acid except proline (Pro)). Changes in the degree of branching and levels of sialylation and fucosylation in $\mathrm{N}$-linked glycans have been reported as a consequence of diseases. Novotny and co-workers recently showed that the $\mathrm{N}$-linked glycans of the prostate cancer patients increased in total fucosylation while the glycans of the healthy individuals had a slight increase in mannosylation [24]. Tabares et al. [3] showed a decrease in the fucose and $\alpha 2,3$-linked sialic acid content of PSA in the patient human serum. They also established differences in glycosylation between the PSAs of the prostate cancer serum and prostate metastatic tumor cell line LNCaP, which may imply that cell lines do not sufficiently represent the physiological environment. In another recent study, glycosylation of haptoglobin in human sera was found to have enhanced branching, sialylation and fucosylation in individuals with prostate cancer [25].

Profiles of N-linked glycans isolated from the immortalized pRNS prostate epithelial cell lines (pRNS) that express wild type or mutant androgen receptors were prepared. Moreover, profiles of N-linked glycans isolated from human sera were obtained from control 
and patient groups. The control group is composed of individuals with low PSA values $(<0.1 \mathrm{ng} / \mathrm{mL})$ who had undergone radical retropubic prostatectomy while the patient group had individuals with elevated PSA values $(5.4-27.0 \mathrm{ng} / \mathrm{mL})$ on active surveillance. The profiles of the two groups were then statistically compared to identify potential biomarkers for prostate cancer.

The goal of this study is to test the hypothesis that glycomics might provide a marker on the presence or absence of prostate cancer in patients who are utilizing PSA. We chose to compare a group of men with no prostate cancer and no prostate to one that had an intact prostate with proven cancer undergoing active surveillance because these groups provide the greatest degree of separation in the samples. We believe that if we could not find differences between these two groups, then there is no way we would find differences between closer subsets.

The comparison of these two groups gives no clinical reason, but rather they are only used in this study to determine feasibility of using glycomics analysis to identify prognostic biomarkers. Our results show glycan differences between the two groups: some high-mannose glycans and acidic glycans were downregulated, while one fucosylated complex-type glycan was up-regulated in the patient group. Future analyses can focus on more relevant patient populations, e.g. compare sera taken from post-prostatectomy men who are monitored for disease recurrence and then correlate the glycan profile with progression-free survival to determine the usefulness of the glycan profile as a prognostic biomarker.

For rapid analysis, we chose to profile globallyreleased $\mathrm{N}$-linked oligosaccharides in these samples without identifying the protein to which they had been attached. Matrix-assisted laser desorption/ionization Fourier transform-ion cyclotron resonance mass spectrometry (MALDI FT-ICR MS) was used to analyze the N-linked glycans. MALDI MS provides a quick method for profiling glycans and is comparatively tolerant to the presence of salts and other contaminants $[26$, 27]. The high resolution and high mass accuracy capabilities of FT-ICR MS gives the glycan compositions, i.e. the numbers of fucose, hexose, $\mathrm{N}$-acetyhexosamine and sialic acid [28].

\section{Materials and methods}

\subsection{Human serum sample}

Twenty serum samples from individuals with prostate cancer $(n=10$, under active surveillance for prostate cancer, PSA $=5.4-27.0 \mathrm{ng} / \mathrm{mL})$ and individuals with their prostate removed ( $n=10$, post-radical retropubic prostatectomy (post-RRP), PSA $<0.1 \mathrm{ng} / \mathrm{mL}$ ) were acquired from the University of California-Davis Medical Center Clinical Laboratories using an IRB-approved protocol. The serum samples were collected by standard venous phlebotomy into red top Vacutainer tubes (or other standard clot-tubes) used for serum chemistry. Samples were frozen at $-80^{\circ} \mathrm{C}$ until processing.

PSA testing was conducted by the UC Davis Medical Center Clinical Laboratory using the ADVIA Centaur PSA assay test on a Bayer ADVIA Centaur (Bayer Diagnostics, Tarrytown, NY). Supplemental Table 1 shows the pathology characteristics of the twenty individuals from whom the serum samples were collected, including the Gleason scores, PSA levels at draw and current PSA, age, pathology stages, pathology margins and pathology dates. The Pathology Stage is a clinical assessment made by the urologist after performing a digital rectal exam (DRE), obtaining a PSA level, and receiving the pathology report from the pathologist who analyzed the biopsy or radical prostatectomy tissue. The Pathology Margin can only be assessed after a radical prostatectomy as the entire prostate is removed from the patient and the pathologist can determine if the cancer went into the surgical margin or if it stopped prior to reaching the margin. This has an important bearing as to the higher risk of recurrence for the margin-positive patients. A biopsy cannot be assessed for margins as a biopsy only obtains small samples of prostate tissue rather than the entire gland, thus the patient group did not have pathology margin data.

The individuals on active surveillance comprising the patient group (P1-P10) were selected based on biopsy proof of having prostate cancer and high PSA levels. It was not possible to get the pathology staging for these individuals as they only had biopsies, no RRPs. Their pathology only indicates Gleason scores, not the extent of cancer (staging) possible by the RRP.

The ten RRP patients comprising the control group, on the other hand, were all stable with PSAs of $<0.1$ and their pathology margins were all negative. These were taken as evidence that they did not have active prostate cancer.

\section{2. pRNS cell lines}

The pRNS-1-1 parental cell line is an SV40immortalized human prostate epithelial cell. pRNS-11 cells were stably transfected with the empty vector, 


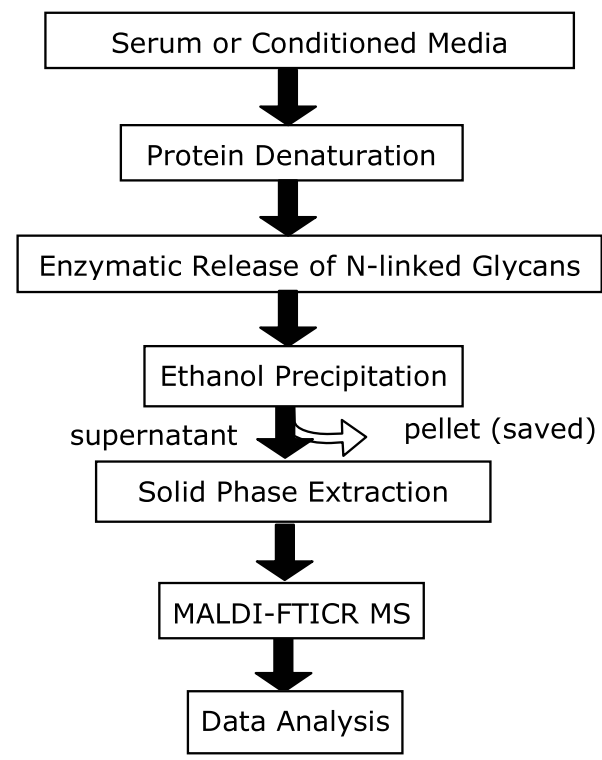

Fig. 1. Workflow of the analysis of N-linked glycans in serum and cell line samples. N-linked glycans were released from denatured glycoproteins by enzymatic digestion using PNGase F. Ethanol was added to precipitate the proteins, leaving the glycans in the supernatant. Fractionation and purification was done by solid phase extraction using graphitized carbon cartridges. Mass spectra were recorded on a ProMALDI FT-ICR MS in six replicates per sample.

wild type androgen receptor (AR), the K580R AR mutant or the T877A AR mutant. The development and characterization of pRNS-1-1 and the pRNS-1-1 sublines used in this study have been described extensively elsewhere [29,30]. The parental pRNS-1-1 cells do not express the AR or PSA [30]. The pRNS-1-1 sublines were routinely maintained in RPMI 1640 supplemented with $5 \%$ fetal bovine serum (FBS) and $50 \mu \mathrm{g} / \mathrm{mL}$ hygromycin. For glycan analysis, $1 \times 10^{6}$ cells were plated in triplicate onto $100 \mathrm{~mm}$ tissue culture dishes and then grown for 3 days in RPMI 1640 supplemented with $5 \%$ FBS prior to collection of the conditioned media. Samples were frozen at $-80^{\circ} \mathrm{C}$ until processing.

\subsection{Enzymatic release of $N$-linked glycans}

Figure 1 shows the flowchart for the analysis of $\mathrm{N}$ linked glycans in the samples. An aliquot of serum or conditioned media from the cell lines $(100 \mu \mathrm{L})$ was mixed with $10 \mathrm{mM}$ dithiothreitol (DTT, Promega, Madison, WI) in $200 \mathrm{mM}$ ammonium bicarbonate $\left(\mathrm{NH}_{4} \mathrm{HCO}_{3}\right.$, Sigma-Aldrich, St. Louis, MO) $(100 \mu \mathrm{L})$ and heated to $100^{\circ} \mathrm{C}$ to denature the proteins.

The N-linked glycans were subsequently released enzymatically using N-glycosidase F (PNGase F, New England Biolabs, Ipswich, MA, $2.5 \mu \mathrm{L})$. The use of
PNGase $\mathrm{F}$ is advantageous since it releases glycans in their original form, regardless of the glycans' size or structure [14]. PNGase F was added after cooling and the mixture was incubated at $37^{\circ} \mathrm{C}$ for $24 \mathrm{~h}$ in a water bath.

Cold ethanol $(800 \mu \mathrm{L})$ was added and the mixture was frozen to $-80^{\circ} \mathrm{C}$ for $1 \mathrm{~h}$ to precipitate the proteins. The N-linked glycans remained in solution (supernatant) and were decanted and dried. The mixture was then centrifuged for $20 \mathrm{~min}$ at $3200 \mathrm{rpm}$.

\subsection{Glycan purification by solid phase extraction}

The recovered supernatant was purified and fractionated by solid phase extraction (SPE) using a graphitized carbon cartridge (Alltech) eluting at increasing concentrations of acetonitrile (ACN) in water. The cartridge was first conditioned with nanopure water, followed by $0.05 \%(\mathrm{v} / \mathrm{v})$ trifluoroacetic acid (TFA) in $80 \%$ acetonitrile $(\mathrm{ACN})$ : water $(\mathrm{v} / \mathrm{v})$, and then by nanopure water. The oligosaccharide solution was loaded onto the cartridge and desalted with nanopure water $(12 \mathrm{~mL})$ at a flow rate of about $1 \mathrm{~mL} / \mathrm{min}$. Glycans were eluted with $10 \% \mathrm{ACN}$ in $\mathrm{H}_{2} \mathrm{O}$ (v/v), $20 \% \mathrm{ACN}$ in $\mathrm{H}_{2} \mathrm{O}(\mathrm{v} / \mathrm{v})$, and $40 \% \mathrm{ACN}$ in $0.05 \%$ TFA in $\mathrm{H}_{2} \mathrm{O}(\mathrm{v} / \mathrm{v})$. Neutral oligosaccharides were eluted in the $10 \%$ and $20 \%$ ACN fractions. The $40 \% \mathrm{ACN}$ fraction contained $0.05 \%$ TFA in its solvent to elute the acidic oligosaccharides. Each fraction was collected and concentrated in vacuo prior to mass spectrometry analysis.

\subsection{Mass spectrometric analysis}

Mass spectra were recorded on an FT-ICR MS with an external source ProMALDI (Varian, Inc., Palo Alto, CA) equipped with a 7.0 Tesla magnet. The ProMALDI was equipped with a pulsed Nd:YAG laser (355 nm). 2,5-dihydroxy-benzoic acid (DHB) was used as a matrix $\left(5 \mathrm{mg} / 100 \mu \mathrm{L}\right.$ in $\left.50 \% \mathrm{ACN}: \mathrm{H}_{2} \mathrm{O}\right)$ for both positive and negative modes. A saturated solution of $\mathrm{NaCl}$ in $50 \%$ ACN: $\mathrm{H}_{2} \mathrm{O}$ was used as a cation dopant. The oligosaccharide solution $(0.5 \mu \mathrm{L})$ was applied to the MALDI probe followed by matrix solution $(0.5 \mu \mathrm{L})$. The sample was dried under vacuum prior to mass spectrometric analysis. Two MALDI spots were prepared per sample, and each spot was divided into three: the upper, middle and lower spots. A spectrum was obtained for each of the three divisions, giving a total of six mass spectral acquisitions per sample. Tandem mass spectrometry using collision-induced dissociation was performed to confirm some of the $\mathrm{N}$-linked glycan compositions. 


\subsection{Data analysis}

Six mass spectral acquisitions per sample were done on the $10 \%, 20 \%$ and $40 \%$ aqueous acetonitrile (ACN) fractions. All spectra were calibrated prior to data analysis using Omega (Ionspec) software. Analysis of the data was performed using in-house programs written in Igor Pro (Wavemetrics).

The mass spectral peaks for each sample were checked against an in-house $\mathrm{N}$-linked glycan library based on accurate mass. The resulting list of N-linked glycans was further filtered based on the following criteria: the peaks should be detected in at least $70 \%$ of the spectra, with at least $1 \%$ intensity, and with intensity changes of at least $20 \%$ between the two groups.

For the comparison of the peaks in the patient and normal samples, statistical analysis using one-way analysis of variance (ANOVA) was performed. If the $\mathrm{p}$-value was less than 0.05 , the difference between the two groups was considered statistically significant.

\section{Results and discussion}

\subsection{Repeatability of the method}

Repeatability is the agreement of individual test results when the method is applied repetitively. The twenty human serum samples were used to test the repeatability of the method. Six mass spectral acquisitions per sample were obtained consecutively in one laboratory session. The number of $\mathrm{N}$-glycans generated for each spectrum was counted and the relative standard deviations were computed. Figure 2 shows the graph of the glycan peaks generated from the $10 \%$ and $20 \% \mathrm{ACN}$ fractions. The relative standard deviations (RSDs) for the $10 \%$ ACN fraction ranged from 2.4 to $12.4 \%$, with a mean value of $7.7 \%$. For the $20 \%$ ACN fraction, the RSDs ranged from 4.7 to $14.7 \%$, with a mean value of $7.9 \%$. More variation was seen in the $40 \% \mathrm{ACN}$ fraction, indicating that acidic species are less stable than the neutral glycans during the MALDI analysis. The $40 \%$ ACN fraction gave an RSD range of $3.5 \%$ to $23.3 \%$ and a mean value of $12.6 \%$ (Supplementary Fig. 1).

\subsection{N-linked glycans in prostate epithelial cell lines}

This method was first performed on prostate epithelial cell lines to demonstrate the application of N-linked glycans and MS analysis for prostate cancer biomarker analysis. The cell lines used were pRNS1-1, an epithelial immortalized prostate cell line, and sub-lines of pRNS1-1 cells that had been stably transfected with the wild type androgen receptor gene or with two separate mutants of the androgen receptor (AR). The AR is a transcription factor that plays a key role in controlling proliferation, differentiation and morphogenesis in the prostate gland. In the normal prostate, the $\mathrm{AR}$ is activated by circulating androgen. A common finding in advanced prostate cancer is that other factors besides androgen, e.g. other steroid hormones and anti-androgens [31], can cause activation of the AR. The consequence of this aberrant activation is that androgen ablation, one of the primary treatments for recurrent metastatic prostate cancer, quickly becomes ineffective and the disease progresses to androgen independent (AI) prostate cancer. This advanced form of prostate cancer is incurable. The ability of the AR to be activated by factors other than androgen has been linked to certain AR mutations [29,32]. It has been documented that androgen receptor mutations occur at a frequency of $27 \%$ to $50 \%$ in advanced prostate cancer [33-35]. Approximately 60 different AR mutations have been described in prostate cancer patients (see http://www.mcgill.ca/androgendb). Hot spot mutations include K580R (located close to the boundary of the hinge and ligand-binding domains) and T877A (located in the primary binding site for p160 co-activators). We are determining if the presence of the AR mutations causes significant glycosylation changes in these cells that can be detected in their conditioned media. This approach is based on the idea that glycosylation of proteins is altered in tumor cells and contribute to the tumorigenesis of the pRNS1-1 sublines that contain the AR mutants. The glycosylation changes can be detected in the conditioned media of these cells just as they might be detected in the serum of prostate cancer patients.

The pRNS-1-1 cell line is an immortalized nontumorigenic androgen dependent prostate cell line that at late passages does not express AR. The sublines assessed in this study were late passage pRNS-1-1 stably transfected with an empty vector control, wild type (WT) AR, and the $\mathrm{AR}^{\mathrm{K} 580 \mathrm{R}}$ or $\mathrm{AR}^{\mathrm{T} 877 \mathrm{~A}}$ mutant alleles. Previous studies have determined that transfection of pRNS-1-1 with the $\mathrm{AR}^{\mathrm{K} 580 \mathrm{R}}$ or $\mathrm{AR}^{\mathrm{T} 877 \mathrm{~A}}$ alleles promotes androgen independent (AI) growth of pRNS-1-1 both in vitro and in vivo, i.e. a phenotype associated with advanced prostate cancer [29]. Soft colony agar assays have also been used to demonstrate that transfection of pRNS-1-1 with either the K580R or 
A

Glycan Peaks Found in the $10 \%$ ACN Fraction

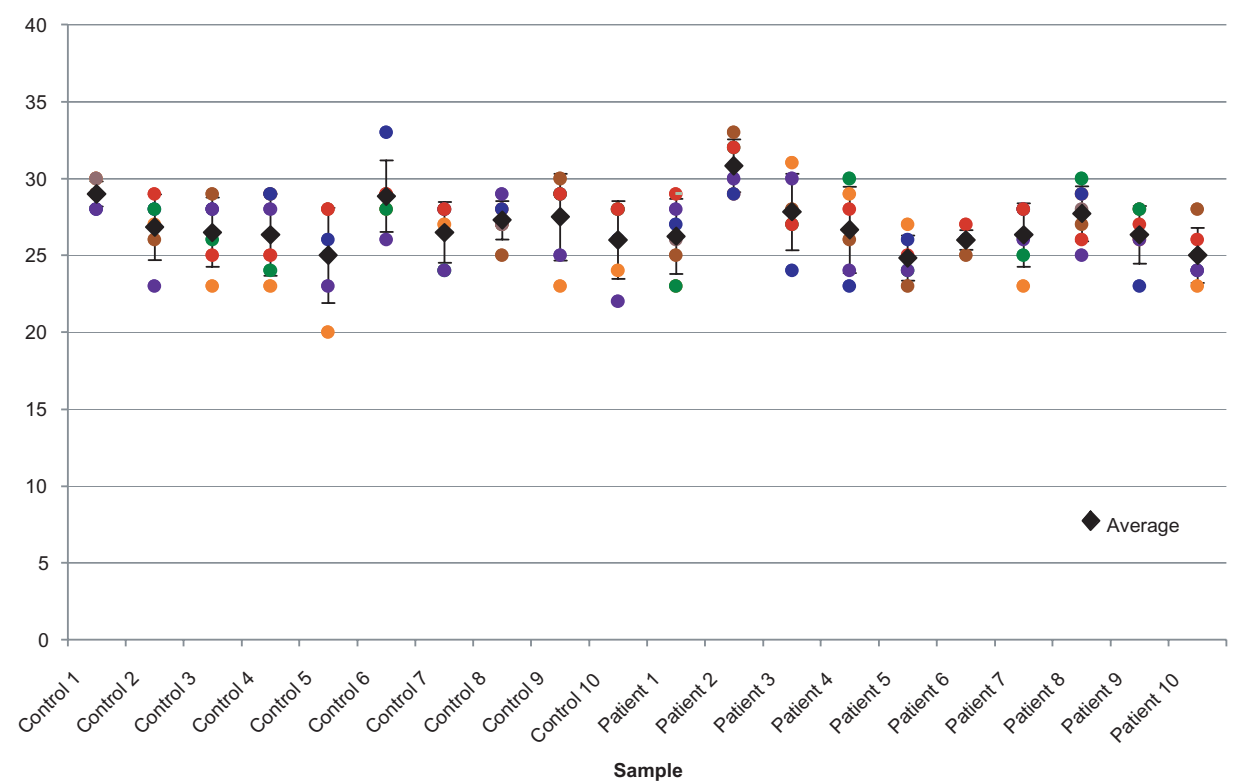

B

Glycan Peaks Found in the $20 \%$ ACN Fraction

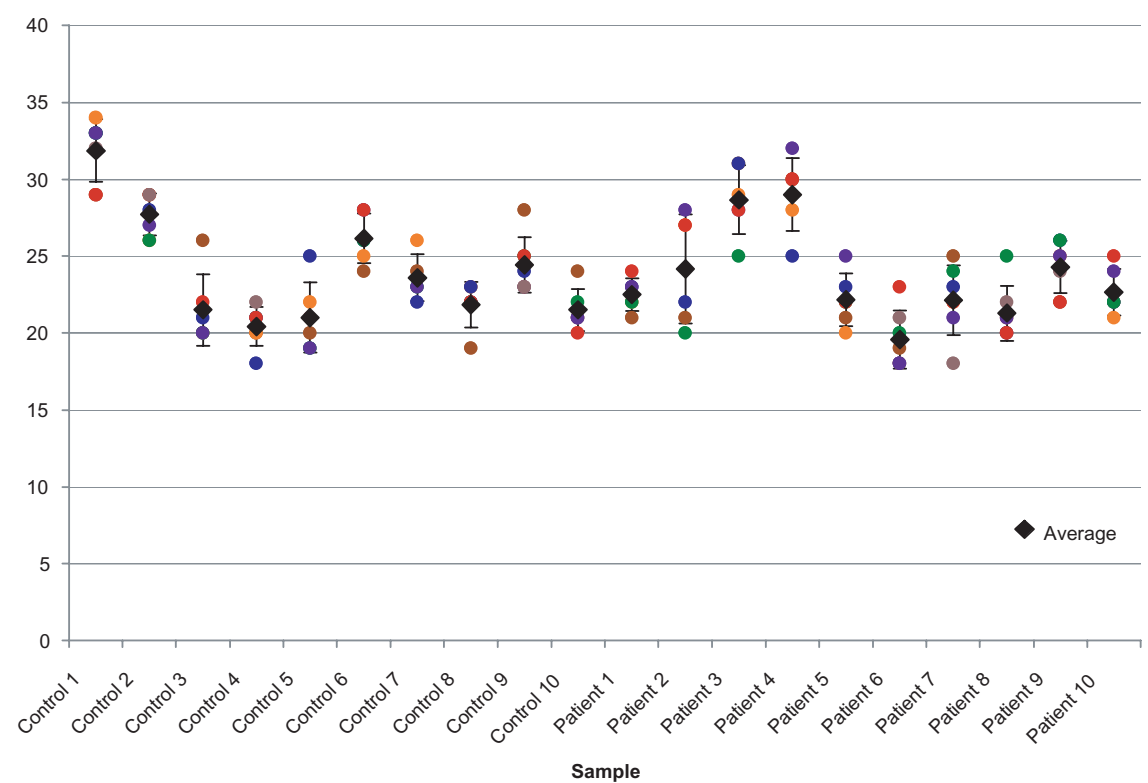

Fig. 2. Number of glycan peaks found in the $10 \%$ and $20 \%$ acetonitrile fractions. Six spectral acquisitions were done for each sample and the relative standard deviations were computed. The relative standard deviations (RSDs) for the $10 \%$ ACN fraction ranged from 2.4 to $12.4 \%$, with a mean value of $7.7 \%$ (Fig. 2A) and for the $20 \% \mathrm{ACN}$ fraction, the RSDs ranged from 4.7 to $14.7 \%$, with a mean value of $7.9 \%$ (Fig. 2B). Bars for standard deviation of the mean are shown for six replicates.

T877A AR mutations results in anchorage-independent growth [29], a growth characteristic that is associated with cancer cells. pRNS-1-1 transfected with emp- ty vector or WT AR was unable to cause androgenindependent or anchorage-independent growth. In these studies, RNA interference analysis was used to 


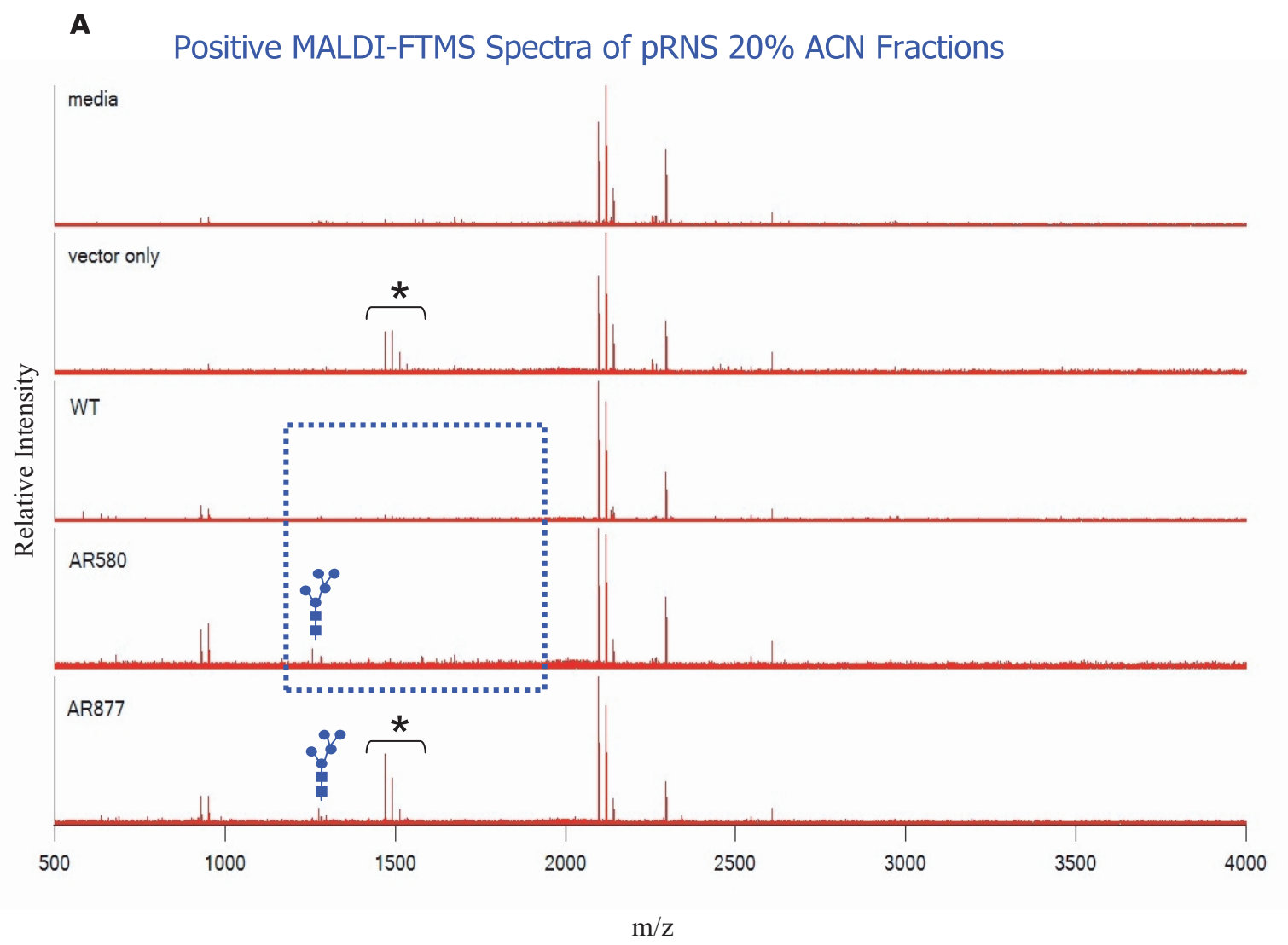

Fig. 3. Comparison of mass spectra of pRNS1-1 samples. (A) MALDI-FTICR MS spectra acquired in the positive mode of the 20\% ACN fraction of cell culture media (media); pRNS cell line with vector alone; pRNS cell line with wild type (WT) androgen receptor (AR); pRNS with the K580R AR mutant (AR580); pRNS1-1 with T877A AR mutant (AR877). (B) Zoom-in on the (B-1) wildtype (WT) and (B-2) AR580. AR877 contains the high-mannose glycans seen in AR580, but major signals correspond to non-glycan peaks. (C) MALDI-FTICR MS spectra acquired in the negative mode of the 40\% ACN fraction from the pRNS1-1 cell lines. Symbol representations of glycans for this figure: GlcNAc, filled square $(\square)$; HexNAc, hollow square $(\square)$; Man, filled circle $(\mathbf{O})$; Hex, hollow circle $(\bigcirc)$; NeuAc, filled diamond $(\bullet)$. GlcNAc $=$ $\mathrm{N}$-acetylglucosamine; HexNAc $=\mathrm{N}$-acetylhexosamine; Man $=$ mannose; Hex $=$ hexose; NeuAc $=$ neuraminic acid or sialic acid. ${ }^{*}$ non-glycan peaks

confirm that these growth characteristics were due to the presence of mutant AR. In vivo experiments confirmed the ability of the pRNS-1-1 cells containing the mutant AR constructs to form tumors in nude mice.

Figure 3A shows the representative spectra of the $20 \%$ ACN fractions of the medium, vector, wild type (WT), AR580 (K380R) and AR877 (T877A) obtained in the positive mode of the MALDI FT-ICR MS. Cell culture media (10\% FBS in RPMI1640) was analyzed as a control. Majority of the glycans were observed in $20 \%$ and $40 \%$ ACN fractions. Significant changes in Nlinked glycans were observed in the $20 \%$ ACN fraction (Fig. 3A) while the $40 \%$ ACN fraction contained the same bovine serum oligosaccharides (Fig. 3C). High mannose N-linked glycans were identified in the mutant samples (Fig. 3B) but not in the medium, vector, or WT samples, suggesting that the increased presence of high mannose N-linked glycans may be an indicator for tumorigenesis of these cell lines. Analysis of spectra from the $40 \%$ ACN fractions (Fig. 3C) showed the presence of complex $\mathrm{N}$-linked oligosaccharides in these samples, but no significant difference was detected between these samples. The same glycans were detected in samples of the culture media indicating that they most likely originated from serum proteins of the fetal bovine serum added to the RPMI cell culture medium.

\subsection{Profile of $N$-linked glycans in human sera}

We next analyzed a small set of serum samples comparing 10 samples from individuals with low PSA values $(<0.1 \mathrm{ng} / \mathrm{mL})$ and had undergone RRP with 
B

B-1 WT

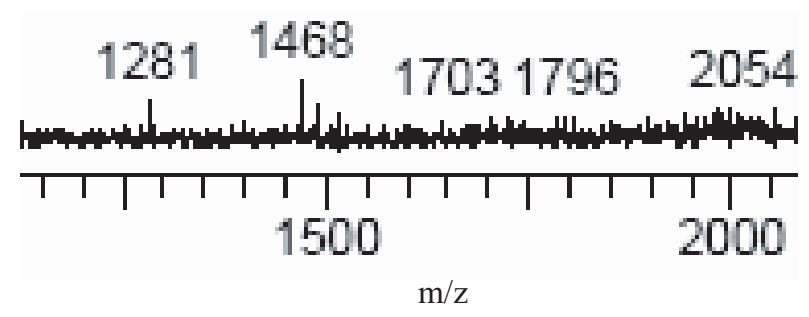

B-2

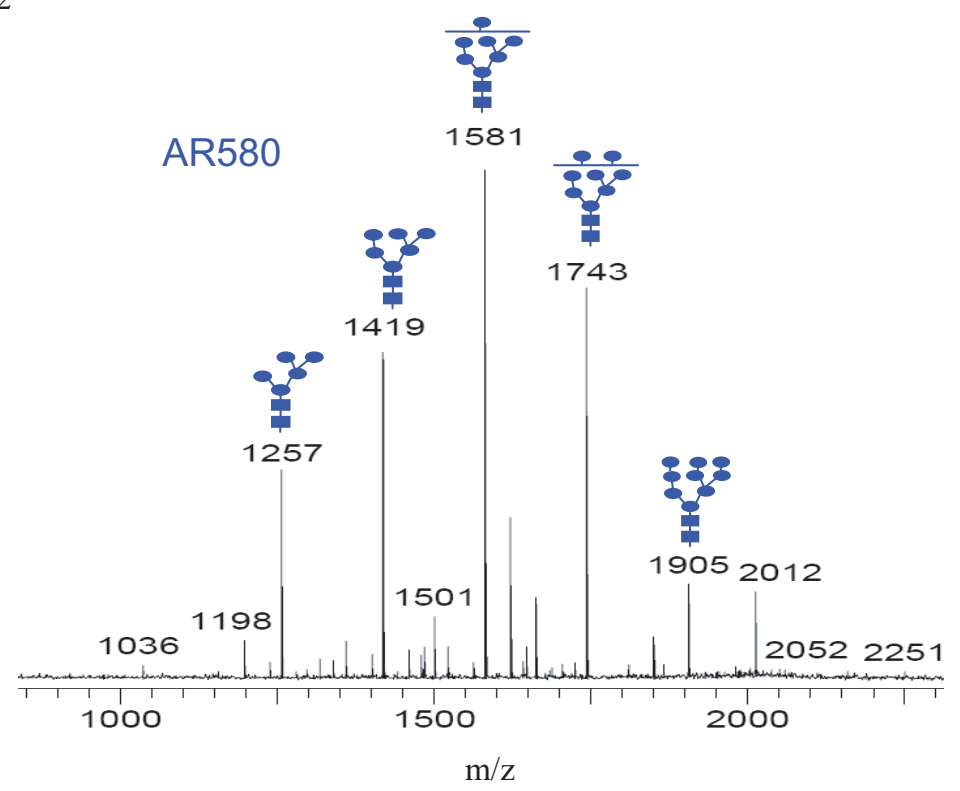

Fig. 3, continued.

no evidence of active disease (control group) and 10 samples from patients with elevated PSA values (5.4$27.0 \mathrm{ng} / \mathrm{mL}$ ) who were on active surveillance (patient group). Figure 4 shows the representative spectra of the 10, 20 and $40 \%$ ACN fractions from the patient group. In the low mass region of the $10 \% \mathrm{ACN}$ spectra acquired in the positive mode, the $\mathrm{N}$-linked glycans are primarily neutral glycans, mostly high-mannose and complex-type glycans with or without fucose. The $20 \%$ ACN fraction contains both the neutral and acidic glycans, thus spectra in both positive and negative ion modes were collected. The acidic glycans, i.e. glycans with at least one sialic acid, elute in the $40 \% \mathrm{ACN}$ fraction and are detected in the negative mode.

The overall profile of the abundant glycans is the same for the patient and control groups. When re- gions of low-intensity masses are amplified, more glycans are observed and the differences between the two groups become more apparent. For instance, Figure 5 shows a bar graph of the $20 \%$ ACN fraction showing the mass-to-charge ratio $(\mathrm{m} / \mathrm{z})$ versus the absolute intensity. The graph shows the $m / z$ values in decreasing intensity. The trend of the peaks for both patient and control groups is quite similar: the most abundant glycan for both groups is $m / z 1647.586$, followed by $\mathrm{m} / z$ 1809.639, $\mathrm{m} / z 1485.534$ and $\mathrm{m} / z$ 1663.581.

Glycan compositions were determined by exact masses obtained from high-resolution mass spectrometry with less than $10 \mathrm{ppm}$ error tolerance. Tandem mass spectrometry using collision-induced dissociation was further performed to confirm the N-linked glycan compositions. Figure 6 shows an example of 


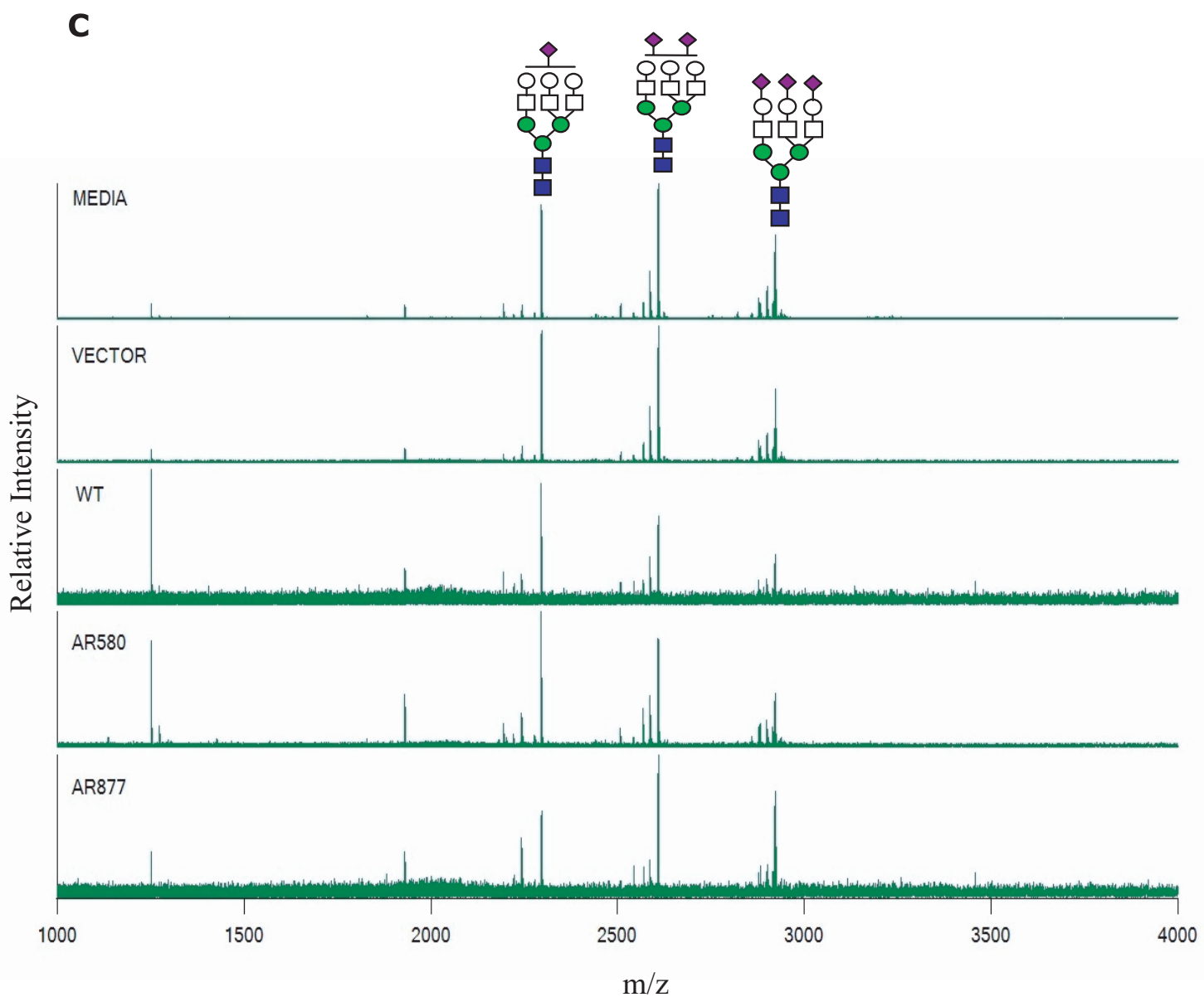

Fig. 3, continued.

an MS/MS spectrum, with $m / z 1809.639$ consisting of $5 \mathrm{Hex}, 4 \mathrm{HexNAc}$, and 1Fuc, and the corresponding monosaccharide losses.

\subsection{Data analyses on the N-linked glycans in human sera}

Based on the set criteria (i.e. peaks should be detected in at least $70 \%$ of the spectra, with at least $1 \%$ intensity and with intensity changes of at least $20 \%$ between the two groups), 24 peaks from the three ACN fractions were obtained (16 neutral glycans and 8 acidic glycans), as shown in Supplemental Table 2. The glycan peaks that were different in the patient and control groups were predominantly high mannose (Man5-Man9, 59Hex: 2HexNAc) and neutral complex-type glycans in the $10 \%$ and $20 \% \mathrm{ACN}$ fractions. For the $40 \% \mathrm{ACN}$ fraction, the glycan peaks identified were mostly sialylated. Fourteen glycans were down-regulated in the patient group while ten were up-regulated. Except for the Man5 glycan $(m / z$ 1257.423), all the identified high-mannose peaks were down-regulated in the patient group. The up-regulation of Man5 in the patient group is consistent with the pRNS cell line observation that Man5 was seen in the mutant samples but not in the medium, vector or wild-type samples. The downregulation of the other high-mannose glycans did not agree with the pRNS cell line results, which showed an up-regulation of the high-mannose glycans in the mutant species. Thus, we find no correlation between the pRNS cell lines and the serum data, which is consistent with the results of Tabares et al. [3]: the cell lines indeed might not be indicative of the actual physiological conditions. Serum is a more complicated glycoprotein mixture and the overall down-regulation of the high mannose glycans may be due to many contributing factors. Aberration in glycosylation may include not just a few low abundance proteins, but potentially every single glycoprotein from a diseased cell. 


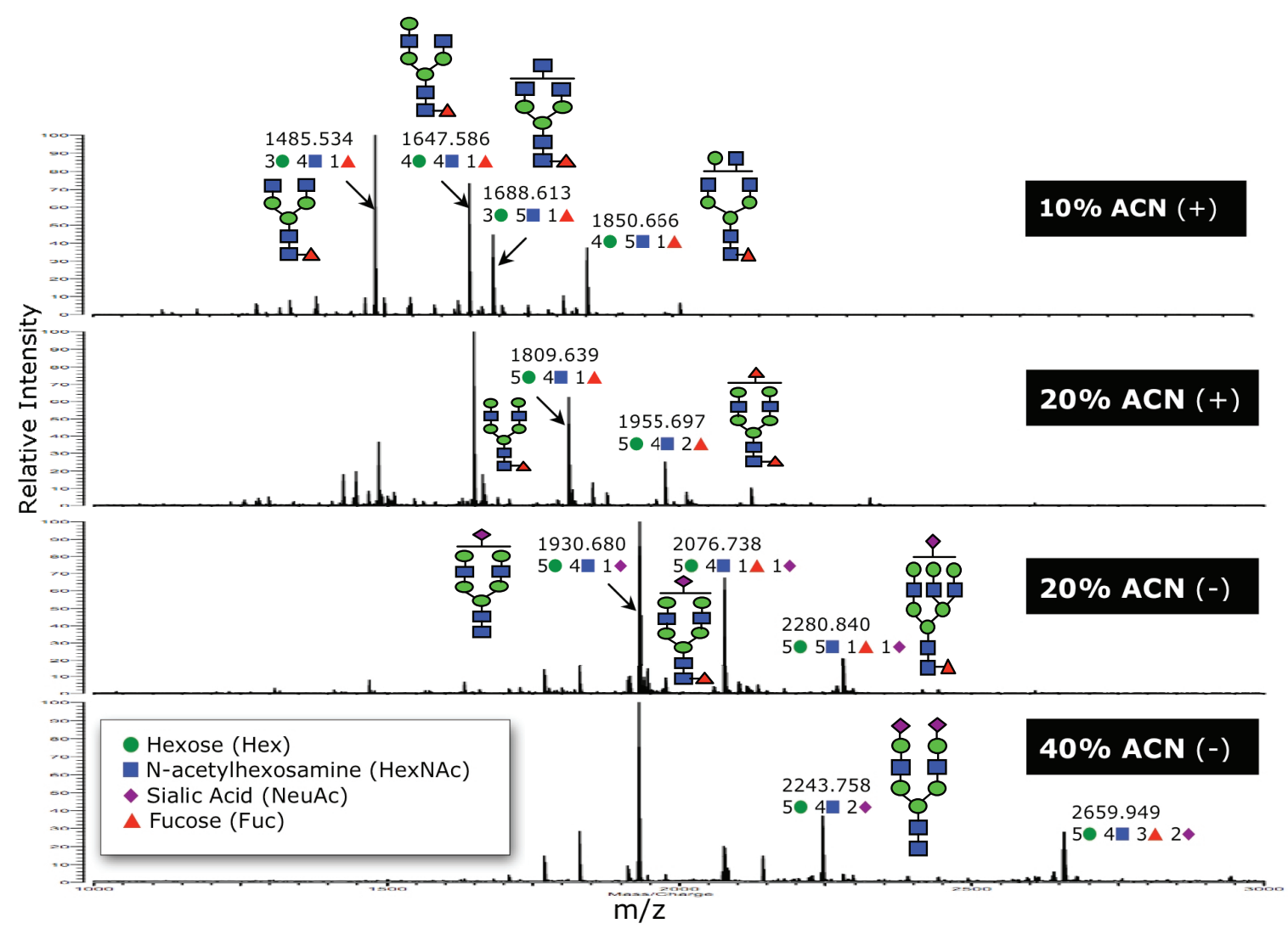

Fig. 4. Representative MALDI FT-ICR mass spectra of N-linked glycans in patient and control sera proteins from the acetonitrile (ACN) fractions analyzed in the positive $(+)$ and negative (-) ion modes. The spectra came from one prostate cancer patient sample. Structures are putative and are based on accurate mass.

However, we find that our results on the downregulation of the high mannose glycans in the human sera of prostate cancer patients are consistent with Novotny's results [24] even if the sample set is different. Our control group are individuals who underwent prostatectomy (post-RRP), i.e. they had their prostate removed.

Eleven fucosylated $\mathrm{N}$-linked glycans were changing between the two groups: six were down-regulated and five were up-regulated in the patient group. The eight sialylated (acidic) glycans are mostly up-regulated in the patient group, except for two: $\mathrm{m} / z 2295.813$ and $m / z 2568.884$. The twelve neutral complex-type glycans were mostly down-regulated in the patient group except for five glycans.

T-tests were then performed and a p-value was obtained for each peak. A p-value of 0.05 or lower was considered statistically significant. The peaks were reduced to seven and are shown in Table 1. Of the seven $\mathrm{N}$-linked glycans, six are down-regulated in the patient group. All the four identified glycans in the $10 \%$
ACN fraction are high-mannose-type glycans (hexose = 6-9) and the two glycans observed in the $20 \%$ ACN fraction are either fucosylated or sialylated complextype glycans differing by one hexose (4:4:1:0, 5:4:0:1 Hex:HexNAc:Fuc:NeuAc). The said acidic (sialylated) glycan $(5: 4: 0: 1)$ is the only up-regulated marker found among the seven potential markers. For the $40 \%$ ACN fraction, only one $\mathrm{N}$-glycan was significantly changing between the control and patient group, and this glycan is both sialylated and fucosylated $(\mathrm{m} / z 2568.884$, 7Hex:4HexNAc:2Fuc:1NeuAc). The two fucosylated glycans (4:4:1:0 and 7:4:2:1) were both down-regulated in the patient group, consistent with Llorens' results [3] in the fucosylation of PSA from the prostate cancer patient serum. Figure 7 shows a bar graph of absolute intensities of the seven identified N-linked glycans.

\section{Summary}

An MS-based method to analyze the N-linked glycans in human sera is being developed. This pilot study 


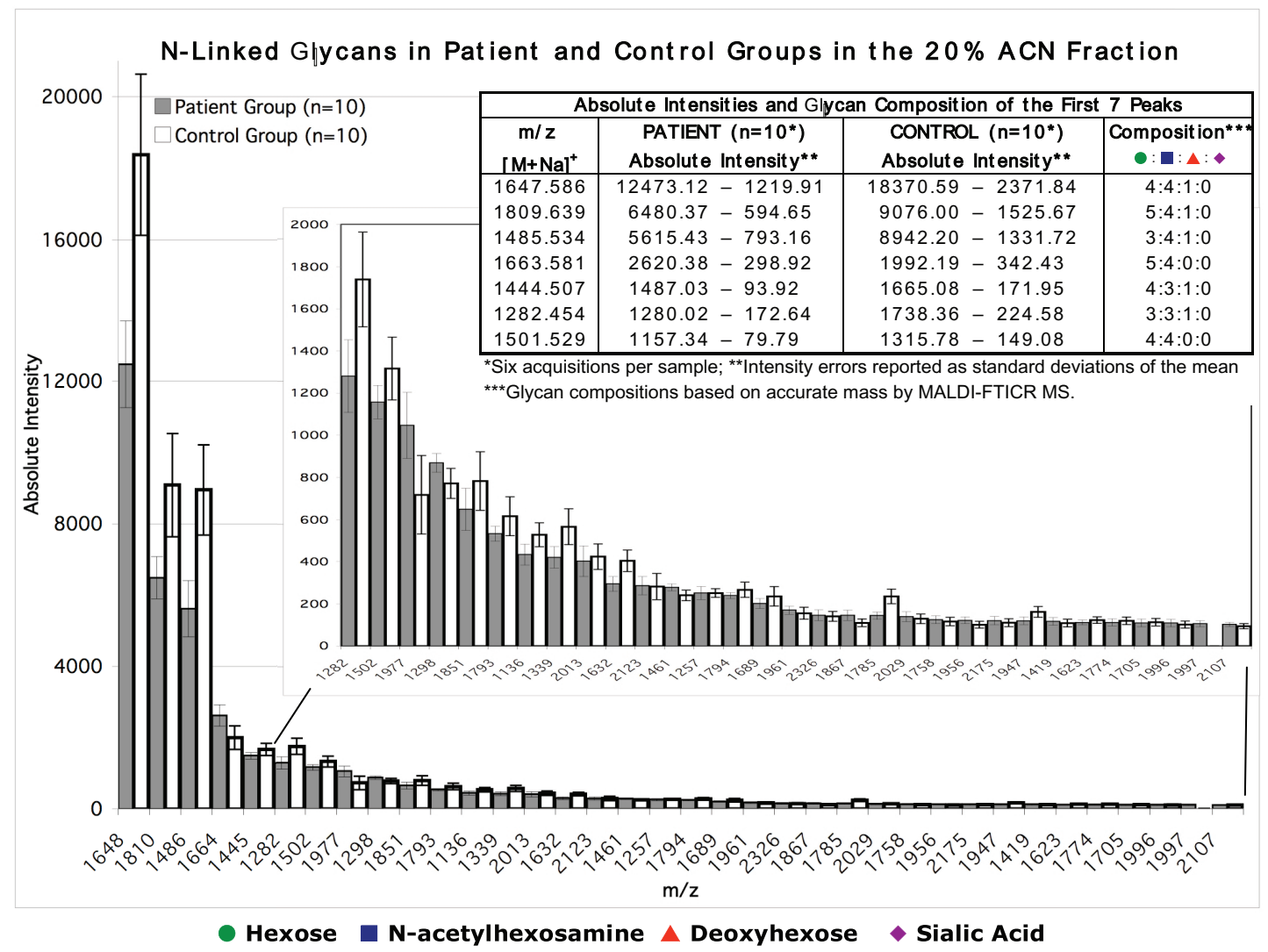

Fig. 5. Profile of N-linked glycans in the $20 \%$ ACN fraction of the serum samples acquired in the positive mode. The $m / z$ values are arranged in order of decreasing absolute intensity. The trend is similar for both the patient and control groups. Bars for standard deviation of the mean are shown for six replicates.

Table 1

The seven possible N-linked glycan biomarkers that are statistically significant $(p<0.05)$ from the three ACN fractions of the serum samples. Glycan compositions are based on the accurate mass as determined by MALDI-FTICR MS.

\begin{tabular}{|c|c|c|c|c|}
\hline $\begin{array}{c}\mathrm{m} / \mathrm{z} \\
{[\mathrm{M}+\mathrm{Na}]^{+}}\end{array}$ & $\begin{array}{l}\text { Composition* } \\
\bigcirc: \square: \triangle: \diamond\end{array}$ & $\begin{array}{c}\text { CONTROL }\left(n=10^{* *}\right) \\
\text { Absolute Intensity }\end{array}$ & $\begin{array}{l}\text { PATIENT }\left(n=10^{* *}\right) \\
\text { Absolute Intensity*** }\end{array}$ & p-value \\
\hline \multicolumn{5}{|c|}{$10 \%$ ACN Fraction } \\
\hline 1419.475 & $6: 2: 0: 0$ & $1884.66 \pm 249.91$ & $1055.98 \pm 195.10$ & 0.018 \\
\hline 1581.528 & $7: 2: 0: 0$ & $539.73 \pm 73.59$ & $286.05 \pm 41.22$ & 0.008 \\
\hline 1743.581 & $8: 2: 0: 0$ & $933.97 \pm 119.38$ & $495.40 \pm 63.45$ & 0.005 \\
\hline 1905.634 & $9: 2: 0: 0$ & $686.63 \pm 149.63$ & $269.58 \pm 26.63$ & 0.014 \\
\hline \multicolumn{5}{|c|}{$20 \%$ ACN Fraction } \\
\hline 1647.586 & $4: 4: 1: 0$ & $23281.62 \pm 3648.92$ & $15047.75 \pm 1262.07$ & 0.047 \\
\hline 1976.659 & $5: 4: 0: 1$ & $752.71 \pm 140.70$ & $1280.81 \pm 192.75$ & 0.040 \\
\hline \multicolumn{5}{|c|}{$40 \%$ ACN Fraction } \\
\hline 2568.884 & $7: 4: 2: 1$ & $139.87 \pm 12.01$ & $106.49 \pm 6.33$ & 0.024 \\
\hline
\end{tabular}

* Glycan compositions based on accurate mass by MALDI-FTICR MS.

$\bigcirc$ Hexose: $\square$ N-Acetylglucosamine: $\triangle$ Fucose: $\diamond$ Sialic Acid

** Six acquisitions per sample

*** Absolute intensity errors reported as standard deviation of the mean

may be useful for future studies since we observed intensity differences in the $\mathrm{N}$-linked glycans between the patient and control groups. Seven potential N-linked glycan biomarkers were identified from the three SPE fractions. These were mostly high mannose type Nlinked glycans.

Four high-mannose (Man6-Man9) type, one neutral and one acidic complex-type glycans are down- 


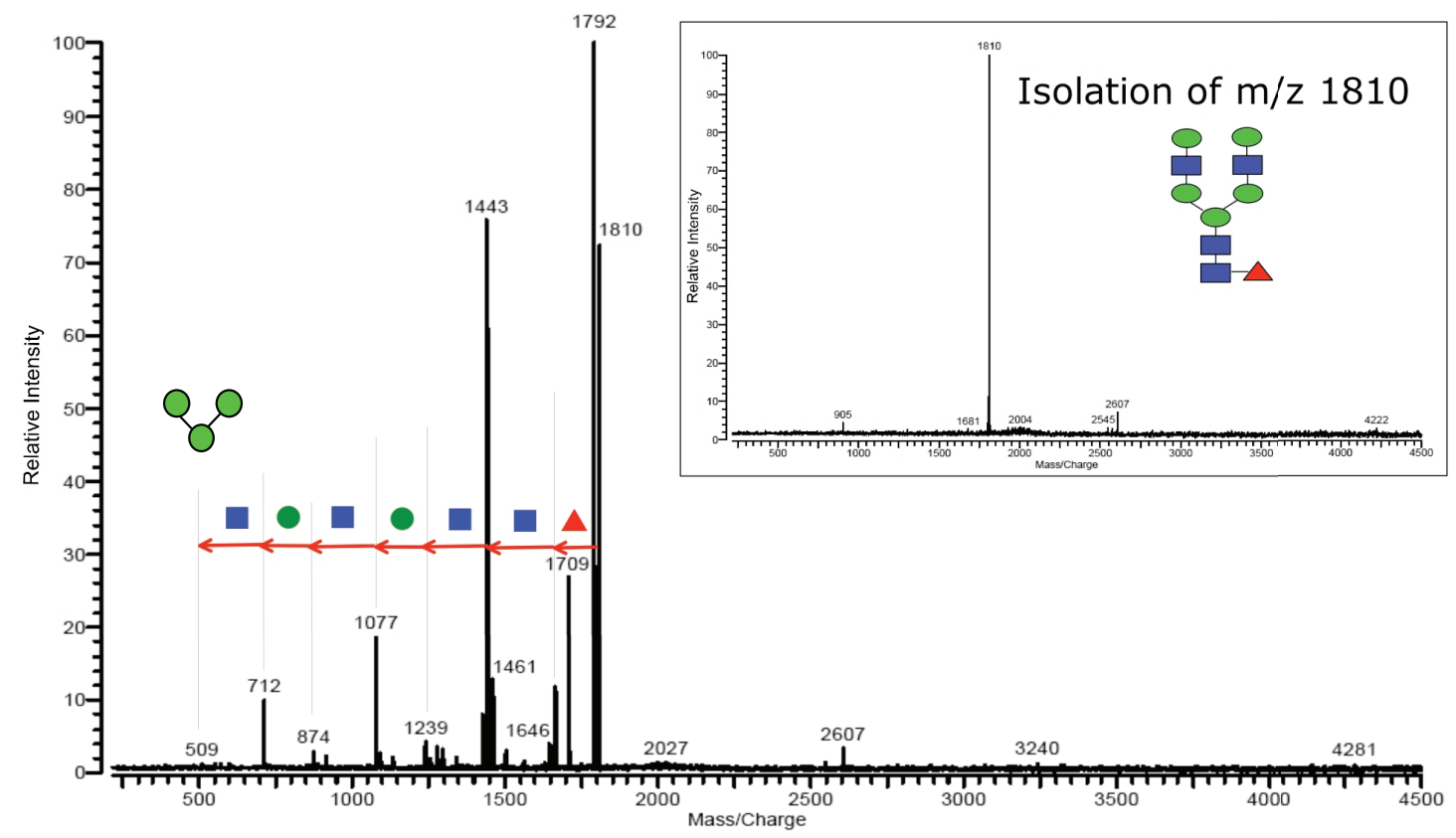

Fig. 6. Collision-induced dissociation of a fucosylated biantennary N-linked glycan with $\mathrm{m} / \mathrm{z}$ 1809.639. The monosaccharide losses based on accurate mass are shown.

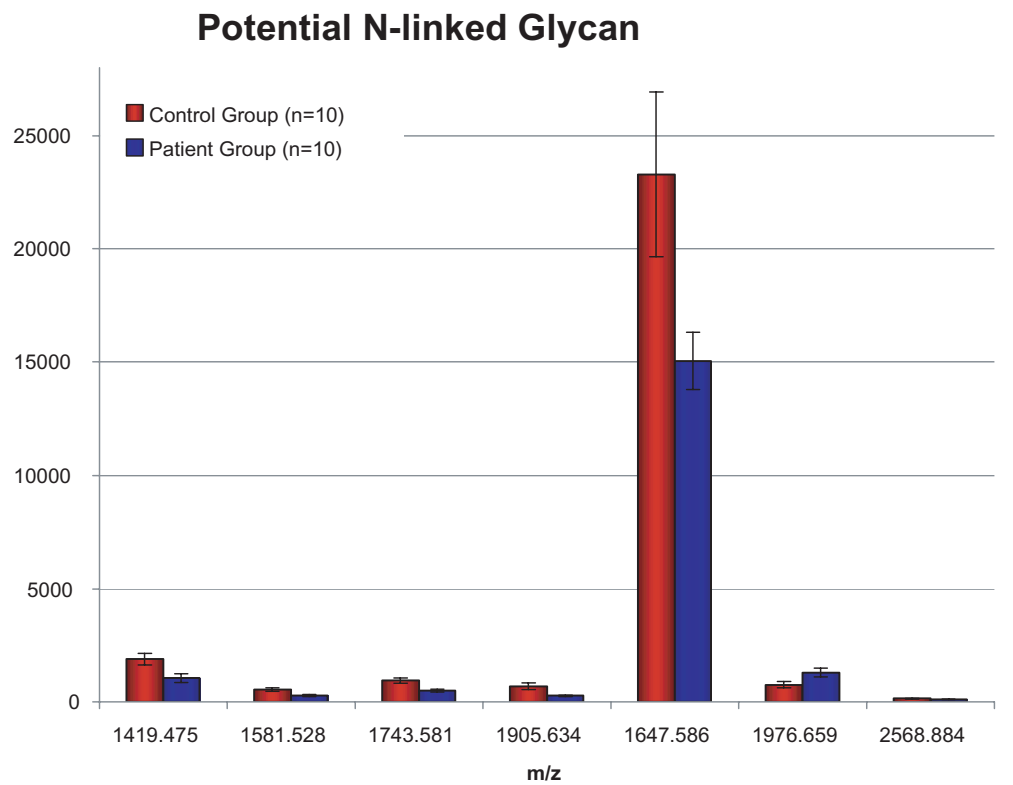

Fig. 7. Graph of absolute intensities of the seven potential N-linked glycan biomarkers that are statistically different $(p<0.05)$ from the control (post-radical retropubic prostatectomy) and patient (under active surveillance) groups. All peaks from the three ACN fractions of the serum samples are down-regulated in the patient group except for one $(\mathrm{m} / \mathrm{z}, 1977)$. Bars for standard deviation of the mean are shown for six replicates.

regulated in the patient group while one acidic complex-type glycan is up-regulated in the patient group with active disease (under active surveillance).
These glycan changes are significantly different from individuals without active disease after having undergone RRP. 
Although further testing and validation of these findings are necessary for future studies, the results suggest that it is possible to use glycomics as a method to obtain potential markers for prostate cancer. To further prove the utility of glycomics in this case, a bigger sample set may be necessary, possibly consisting of a) men with normal prostates, b) men with $\mathrm{BPH}, \mathrm{c}$ ) men who have localized prostate cancer, d) men who have elevated and e) lowered PSAs after radical prostatectomies and f) men who have metastatic disease prior to and g) after initiation of hormonal therapy. A big undertaking such as this is warranted given the positive results presented in this study. Moreover, the collection of blood samples from these individuals should be time-controlled in subsequent studies, to avoid variation due to physical trauma or inflammation following surgery.

\section{Acknowledgements}

The pRNS-1-1 cells and mutants were kindly provided by Dr. Xu-Bao Shi (University of California, Davis, CA). The pRNS-1-1 parental cell line was originally provided by Dr. Johng Rhim (University of the Health Sciences, Bethesda, MD). We also acknowledge the assistance of Dr. Arline D. Deitch in the editing and proofreading of this manuscript, and Crystal Kirmiz for training the first author. We are thankful for the grants from NIH ROI GM 049077 (to CBL) and DOD Prostate Cancer IMPACT Program W81XWH06-1-0011 (to SM).

\section{Abbreviations}

ACN: acetonitrile

BPH: benign prostate hyperplasia

IRMPD: infrared multiphoton dissociation

MALDI FT-ICR MS: matrix-assisted laser desorption/ioniz-ation-Fourier transform ion-cyclotron resonance mass spectrometry (or spectrometer)

PNGase F: peptide $N$-glycosidase F from Flavobacterium meningosepticum

PSA: prostate-specific antigen

RRP: radical retropubic prostatectomy

RSD: relative standard deviation

TFA: trifluoroacetic acid

\section{References}

[1] A. Jemal, R. Siegel, E. Ward, Y. Hao, J. Xu, T. Murray and M.J. Thun, Cancer Statistics, CA: a cancer Journal for Clinicians, 2008.

[2] National-Cancer-Institute, What You Need to Know About Prostate Cancer, 2005.

[3] G. Tabares, C.M. Radcliffe, S. Barrabes, M. Ramirez, R.N. Aleixandre, W. Hoesel, R.A. Dwek, P.M. Rudd, R. Peracaula and R.d. Llorens, Different Glycan Structures in Prostatespecific Antigen from Prostate Cancer Sera in Relation to Seminal Plasma PSA, Glycobiology 16 (2006), 132-145.

[4] C. Stephan, K. Jung, M. Lein and E.P. Diamandis, PSA and Other Tissue Kallikreins for Prostate Cancer Detection, European Journal of Cancer 43 (2007), 1918-1926.

[5] R. Peracaula, G. Tabares, L. Royle, D.J. Harvey, R.A. Dwek, P.M. Rudd and R.d. Llorens, Altered Glycosylation Pattern Allows the Distinction between Prostate-specific Antigen (PSA) from Normal and Tumor Origins, Glycobiology 13 (2003), 457-470.

[6] I.M. Thompson, D.K. Pauler, P.J. Goodman, C.M. Tangen, M.S. Lucia, H.L. Parnes, L.M. Minasian, L.G. Ford, S.M. Lippman, E.D. Crawford, J.J. Crowley and C.A. Jr. Coltman, Prevalence of prostate cancer among men with a prostatespecific antigen level $<$ or $=4.0 \mathrm{ng}$ per milliliter, The New England journal of medicine 350 (2004), 2239-2246.

[7] D.J. Parekh, D.P. Ankerst, D. Troyer, S. Srivastava and I.M. Thompson, Biomarkers for prostate cancer detection, J Urol 178 (2007), 2252-2259.

[8] O.P. Bondar, D.R. Barnidge, E.W. Klee, B.J. Davis and G.G. Klee, LC-MS/MS Quantification of Zn- $\alpha 2$ Glycoprotein: A Potential Serum Biomarker for Prostate Cancer, Clinical Chemistry 53 (2007), 673-678.

[9] D. Maraldo, F.U. Garcia and R. Mtharasan, Method for Quantification of a Prostate Cancer Biomarker in Urine without Sample Preparation, Analytical Chemistry 79 (2007), 76837690.

[10] B. Matharoo-Ball, G. Ball and R. Rees, Clinical Proteomics: Discovery of Cancer Biomarkers using Mass Spectrometry and Bioinformatics Approaches-A Prostate Cancer Perspective, Vaccine 25S (2007), B110-B121.

[11] M. Hellstrom, S. Jonmarker, J. Lehtio, G. Auer and L. Egevad, Proteomics in Clinical Prostate Research, Proteomics: Clinical Applications 1 (2007), 1058-1065.

[12] M.W. Datta, L.D. True, P.S. Nelson and M.B. Amin, The Role of Tissue Microarrays in Prostate Cancer Biomarker Discovery, Advances in Anatomic Pathology 14 (2007), 408-418.

[13] G. Sardana, J. Marshall and E.P. Diamandis, Discovery of Candidate Tumor Markers for Prostate Cancer via Proteomic Analysis of Cell Culture-Conditioned Medium, Clinical Chemistry 53 (2007), 429-437.

[14] Y. Kita, Y. Miura, J.-I. Furukawa, M. Nakano, U. Shinohara, M. Ohno, A. Takimoto and S.-I. Nishimura, Quantitative Glycomics of Human Whole Serum Glycoproteins Based on the Standardized Protocol for Liberating N-Glycans, Molecular and Cellular Proteomics 6 (2007), 1437-1445.

[15] S. Hakomori, Glycosylation Defining Cancer Malignancy: New Wine in an Old Bottle, Proceedings of the National Academy of Sciences of the United States of America 99 (2002), 10231-10233.

[16] T.-Y.Chou and G.W. Hart, O-linked N-acetylglucosamine and Cancer: Messages from the Glycosylation of C-Myc, Advances in Experimental Medicine and Biology 491 (2001), 413-418. 
[17] M.A. Hollingsworth and B.J. Swanson, Mucins in cancer: protection and control of the cell surface, Nature reviews 4 (2004), 45-60.

[18] H.F. Valenzuela, K.E. Pace, P.V. Cabrera, R. White, K. Porvari, H. Kaija, P. Vihko and L.G. Baum, O-Glycosylation Regulates LNCaP Prostate Cancer Cell Susceptibility to Apoptosis Induced by Galectin-1, Cancer Research 67 (2007), 6155-6162.

[19] R.A. Dwek, Glycobiology: Toward Understanding the Function of Sugars, Chemical Reviews 96 (1996), 683-720.

[20] D.J. Harvey, Proteomic Analysis of Glycosylation: Structural Determination of N- and O-linked Glycans by Mass Spectrometry, Expert Review of Proteomics 2 (2005), 87-101.

[21] A. Kobata and J. Amano, Altered Glycosylation of Proteins Produced by Malignant Cells, and Application for the Diagnosis and Immunotherapy of Tumours, Immunology and Cell Biology 83 (2005), 429-439.

[22] H.J. An, S. Miyamoto, K.S. Lancester, C. Kirmiz, B. Li, K.S Lam, G.S. Leiserowitz and C.B. Lebrilla, Profiling of Glycans in Serum for the Discovery of Potential Biomarkers for Ovarian Cancer, Journal of Proteome Research 5 (2006), 16261635.

[23] C. Kirmiz, B. Li, H.J. An, B.H. Clowers, H.K. Chew, K.S. Lam, A. Ferrige, R. Alecio, A.D. Borowsky, S. Sulaimon, C.B. Lebrilla and S. Miyamoto, A Serum Glycomics Approach to Breast Cancer Biomarkers, Molecular and Cellular Proteomics 6 (2007), 43-55.

[24] Z. Kyselova, Y. Mechref, M.M. Al Bataineh, L.E. Dobrolecki, R.J. Hickey, J. Vinson, C.J. Sweeney and M.V. Novotny, Alterations in the serum glycome due to metastatic prostate cancer, J Proteome Res 6 (2007), 1822-1832.

[25] T. Fujimura, Y. Shinohara, B. Tissot, P.-C. Pang, M. Kurogochi, S. Saito, Y. Arai, M. Sadilek, K. Murayama, A. Dell, S.-I. Nishimura and S.-I. Hakomori, Glycosylation Status of Haptoglobin in Sera of Patients with Prostate Cancer vs. Benign Prostate Disease or Normal Subjects, Int J Cancer 122 (2008), 39-49.

[26] D.J. Harvey, Structural determination of N-linked glycans by matrix-assisted laser desorption/ionization and electrospray ionization mass spectrometry, Proteomics 5 (2005), 17741786.

[27] J. Zaia, Mass spectrometry of oligosaccharides, Mass spectrometry reviews 23 (2004), 161-227.
[28] Y. Park and C.B. Lebrilla, Application of Fourier transform ion cyclotron resonance mass spectrometry to oligosaccharides, Mass spectrometry reviews 24 (2005), 232-264.

[29] X.-B. Shi, X. Lingru, C.G. Tepper, R. Gandour-Edwards, P. Ghosh, H.-J. Kung and R.W.d.V. White, The Oncogenic Potential of a Prostate Cancer-derived Androgen Receptor Mutant, Prostate 67 (2007), 591-602.

[30] M.S. Lee, E. Garkovenko, J.S. Yun, P.C. Weijerman, D.M. Peehl, L.S. Chen and J.S. Rhim, Characterization of Adult Human Prostatic Epithelial Cells Immortalized by Polybreneinduced DNA Transfection with a Plasmid Containing an Origin-defective SV40 Genome, Int J Oncol 4 (1994), 821830.

[31] J. Veldsholte, C.A. Berrevoets, C. Ris-Stalpers, G.G.J.M. Kuiper, G. Jenster, J. Trapman, A.O. Brinkmann and E. Mulder, The Androgen Receptor in LNCaP Cells Contains a Mutation in the Ligand Binding Domain Which Affects Steroid Binding Characteristics and Response to Antiandrogens, Journal of Steroid Biochemistry and Molecular Biology 41 (1992), 665-669.

[32] G. Han, G. Buchanan, M. Ittmann, J.M. Harris, X. Yu, F.J. DeMayo, W. Tilley and N.M. Greenberg, Mutation of the Androgen Receptor Causes Oncogenic Transformation of the Prostate, Proceedings of the National Academy of Sciences of the United States of America 102 (2005), 1151-1156.

[33] M. Marcelli, M. Ittmann, S. Mariani, R. Sutherland, R. Nigam, L. Murthy, Y. Zhao, D. DiConcini, E. Puxeddu, A. Esen, J. Eastham, N.L. Weigel and D.J. Lamb, Androgen Receptor Mutations in Prostate Cancer, Cancer Research 60 (2000), 944-949.

[34] M.-E. Taplin, G.J. Bubley, T.D. Shuster, M.E. Frantz, A.E. Spooner, G.K. Ogata, H.N. Keer and S.P. Balk, Mutation of the Androgen-receptor Gene in Metastatic Androgen-independent Prostate Cancer, New England Journal of Medicine 332 (1995), 1393-1398.

[35] W.D. Tilley, G. Buchanan, T.E. Hickey and J.M. Bentel, Mutations in the Androgen Receptor Gene are Associated with Progression of Human Prostate Cancer to Androgen Independence Clinical Cancer Research 2 (1996), 277-285. 
Supplemental Table 1

Pathology information of the individuals in the control (C1-C10) and patient (P1-P10) groups of the serum samples. AS = active surveillance; RRP = radical retropubic prostatectomy

\begin{tabular}{|c|c|c|c|c|c|c|c|c|}
\hline $\begin{array}{c}\text { Lab } \\
\text { Code }\end{array}$ & $\begin{array}{c}\text { Gleason } \\
\text { Score }\end{array}$ & $\begin{array}{c}\text { PSA at Draw } \\
(\mathrm{ng} / \mathrm{mL})\end{array}$ & $\begin{array}{c}\text { Last PSA } \\
(\mathrm{ng} / \mathrm{mL})\end{array}$ & Age & Treatment & $\begin{array}{l}\text { Pathology } \\
\text { Stage }\end{array}$ & $\begin{array}{c}\text { Pathology } \\
\text { Margins }\end{array}$ & $\begin{array}{c}\text { Pathology } \\
\text { Date }\end{array}$ \\
\hline P1 & 6 & 10.9 & 16.79 & 75 & $\mathrm{AS}$ & * & * & $11 / 1 / 04$ \\
\hline $\mathrm{P} 2$ & 6 & 7.7 & 6.1 & 66 & AS & * & * & $6 / 1 / 05$ \\
\hline P3 & 5 & 7.9 & 11.2 & 65 & AS & * & * & $5 / 23 / 05$ \\
\hline $\mathrm{P} 4$ & 6 & 5.4 & 8.5 & 80 & AS & * & * & $8 / 25 / 05$ \\
\hline P5 & 6 & 27 & 21.6 & 71 & AS & * & * & $8 / 15 / 05$ \\
\hline P7 & 6 & 5.9 & 6.3 & 53 & AS & * & * & $10 / 6 / 05$ \\
\hline P6 & 6 & 5.7 & 6.4 & 66 & AS & * & * & $10 / 5 / 05$ \\
\hline P8 & 6 & 7 & 8.7 & 71 & AS & * & * & $10 / 20 / 05$ \\
\hline P9 & 6 & 5.8 & 4.9 & 63 & AS & * & * & $11 / 1 / 05$ \\
\hline $\mathrm{P} 10$ & 6 & 12.2 & 10.9 & 81 & AS & * & * & $11 / 9 / 05$ \\
\hline N1 & 7 & $<0.1$ & $<0.1$ & 72 & RRP & $\mathrm{pT} 2 \mathrm{a}$ & Negative & $1 / 9 / 06$ \\
\hline $\mathrm{N} 2$ & 7 & $<0.1$ & $<0.1$ & 69 & RRP & pT2b & Negative & $1 / 19 / 06$ \\
\hline N3 & 7 & $<0.1$ & $<0.1$ & 54 & RRP & $\mathrm{pT} 2 \mathrm{a}$ & Negative & $2 / 2 / 06$ \\
\hline N4 & 6 & $<0.1$ & $<0.1$ & 53 & RRP & pT2b & Negative & $3 / 6 / 06$ \\
\hline N5 & 7 & $<0.1$ & $<0.1$ & 59 & RRP & pT $2 c$ & Negative & $4 / 10 / 06$ \\
\hline N6 & 6 & $<0.1$ & $<0.1$ & 61 & RRP & pT $2 b$ & Negative & $4 / 24 / 06$ \\
\hline N7 & 6 & $<0.1$ & $<0.1$ & 62 & RRP & pT1c & Negative & $4 / 28 / 06$ \\
\hline N8 & 7 & $<0.1$ & $<0.1$ & 56 & RRP & pT2c & Negative & $6 / 5 / 06$ \\
\hline N9 & 7 & $<0.1$ & $<0.1$ & 58 & RRP & pT3a & Negative & $6 / 5 / 06$ \\
\hline N10 & 7 & $<0.1$ & $<0.1$ & 57 & RRP & pT3a & Negative & $6 / 6 / 06$ \\
\hline
\end{tabular}

*Active surveillance patients not pathologically staged (biospy only).

Supplemental Table 2

Filtered glycan peaks based on the set criteria on abundance, frequency and delta for the three ACN fractions using MALDI FT-ICR MS. The $\mathrm{m} / z$ values shown in bold are significantly changing between the two groups based on t-test (p-value < 0.05) The glycan composition is based on accurate mass.

\begin{tabular}{|c|c|c|c|c|}
\hline $\begin{array}{c}\mathrm{m} / \mathrm{z} \\
{[\mathrm{M}+\mathrm{Na}]^{+}}\end{array}$ & $\begin{array}{l}\text { Composition* } \\
\bigcirc: \square: \triangle: \diamond\end{array}$ & $\begin{array}{c}\text { CONTROL }\left(n=10^{* *}\right) \\
\text { Absolute Intensity }\end{array}$ & $\begin{array}{l}\left.\text { PATIENT ( } n=10^{* *}\right) \\
\text { Absolute Intensity*** }\end{array}$ & p-value \\
\hline \multicolumn{5}{|c|}{ Filtered Peaks in the $10 \%$ ACN Fraction } \\
\hline 1257.423 & $5: 2: 0: 0$ & $869.46 \pm 96.92$ & $1100.88 \pm 152.84$ & 0.217 \\
\hline 1419.475 & $6: 2: 0: 0$ & $1884.66 \pm 249.91$ & $1055.98 \pm 195.10$ & 0.018 \\
\hline 1581.528 & $7: 2: 0: 0$ & $539.73 \pm 73.59$ & $286.05 \pm 41.22$ & 0.008 \\
\hline 1622.555 & $6: 3: 0: 0$ & $701.23 \pm 128.52$ & $440.75 \pm 63.77$ & 0.086 \\
\hline 1663.581 & $5: 4: 0: 0$ & $1221.28 \pm 139.51$ & $1508.57 \pm 299.23$ & 0.396 \\
\hline 1743.581 & $8: 2: 0: 0$ & $933.97 \pm 119.38$ & $495.40 \pm 63.45$ & 0.005 \\
\hline 1825.634 & $6: 4: 0: 0$ & $275.27 \pm 42.71$ & $179.18 \pm 28.26$ & 0.085 \\
\hline 1905.634 & $9: 2: 0: 0$ & $686.63 \pm 149.63$ & $269.58 \pm 26.63$ & 0.014 \\
\hline \multicolumn{5}{|c|}{ Filtered Peaks in the $20 \%$ ACN Fraction } \\
\hline 1282.454 & $3: 3: 1: 0$ & $1899.38 \pm 368.99$ & $1450.04 \pm 166.54$ & 0.282 \\
\hline 1339.476 & $3: 4: 0: 0$ & $648.16 \pm 143.87$ & $484.04 \pm 43.40$ & 0.289 \\
\hline 1485.534 & $3: 4: 1: 0$ & $10573.93 \pm 1799.03$ & $6581.71 \pm 858.37$ & 0.060 \\
\hline 1647.586 & $4: 4: 1: 0$ & $23281.62 \pm 3648.92$ & $15047.75 \pm 1262.07$ & 0.047 \\
\hline 1663.581 & 5:4:0:0 & $2673.90 \pm 535.23$ & $3234.04 \pm 341.47$ & 0.389 \\
\hline 1809.639 & $5: 4: 1: 0$ & $12619.49 \pm 3112.12$ & $8047.16 \pm 702.73$ & 0.169 \\
\hline 1976.659 & $5: 4: 0: 1$ & $752.71 \pm 140.70$ & $1280.81 \pm 192.75$ & 0.040 \\
\hline \multicolumn{5}{|c|}{ Filtered Peaks in the $40 \%$ ACN Fraction } \\
\hline 2082.725 & $4: 4: 2: 1$ & $409.80 \pm 55.70$ & $517.12 \pm 42.53$ & 0.143 \\
\hline 2084.717 & $9: 3: 0: 0$ & $199.23 \pm 23.29$ & $252.08 \pm 26.24$ & 0.149 \\
\hline 2295.813 & $6: 5: 0: 1$ & $1231.82 \pm 127.72$ & $943.51 \pm 86.20$ & 0.078 \\
\hline 2296.833 & $6: 5: 2: 0$ & $1204.20 \pm 121.10$ & $928.00 \pm 81.98$ & 0.075 \\
\hline 2389.816 & $5: 4: 1: 2$ & $244.88 \pm 19.34$ & $295.84 \pm 28.07$ & 0.152 \\
\hline
\end{tabular}


Supplemental Table 2, continued

\begin{tabular}{ccccc}
\hline $\begin{array}{c}\mathrm{m} / \mathrm{z} \\
{[\mathrm{M}+\mathrm{Na}]^{+}}\end{array}$ & $\begin{array}{c}\text { Composition* } \\
\bigcirc: \square: \triangle: \diamond\end{array}$ & $\begin{array}{c}\text { CONTROL }\left(n=10^{* *}\right) \\
\text { Absolute Intensity*** }\end{array}$ & $\begin{array}{c}\text { PATIENT }\left(n=10^{* *}\right) \\
\text { Absolute Intensity*** }\end{array}$ & p-value \\
\hline 2390.836 & $5: 4: 3: 1$ & $251.69 \pm 16.79$ & $313.49 \pm 30.85$ & 0.096 \\
2568.884 & $7: 4: 2: 1$ & $139.87 \pm 12.01$ & $106.49 \pm 6.33$ & 0.024 \\
2754.948 & $6: 5: 1: 2$ & $115.14 \pm 9.21$ & $147.16 \pm 18.51$ & 0.139 \\
2755.968 & $6: 5: 3: 1$ & $124.51 \pm 11.41$ & $173.80 \pm 22.40$ & 0.066 \\
\hline
\end{tabular}

${ }^{*}$ Glycan compositions based on accurate mass by MALDI-FTICR MS.

$\bigcirc$ Hexose: $\square$ N-Acetylglucosamine: $\triangle$ Fucose: $\backslash$ Sialic Acid.

${ }^{* *}$ Six acquisitions per sample.

*** Absolute intensity errors reported as standard deviation of the mean.

\section{Glycan Peaks Found in the $40 \%$ ACN Fraction}

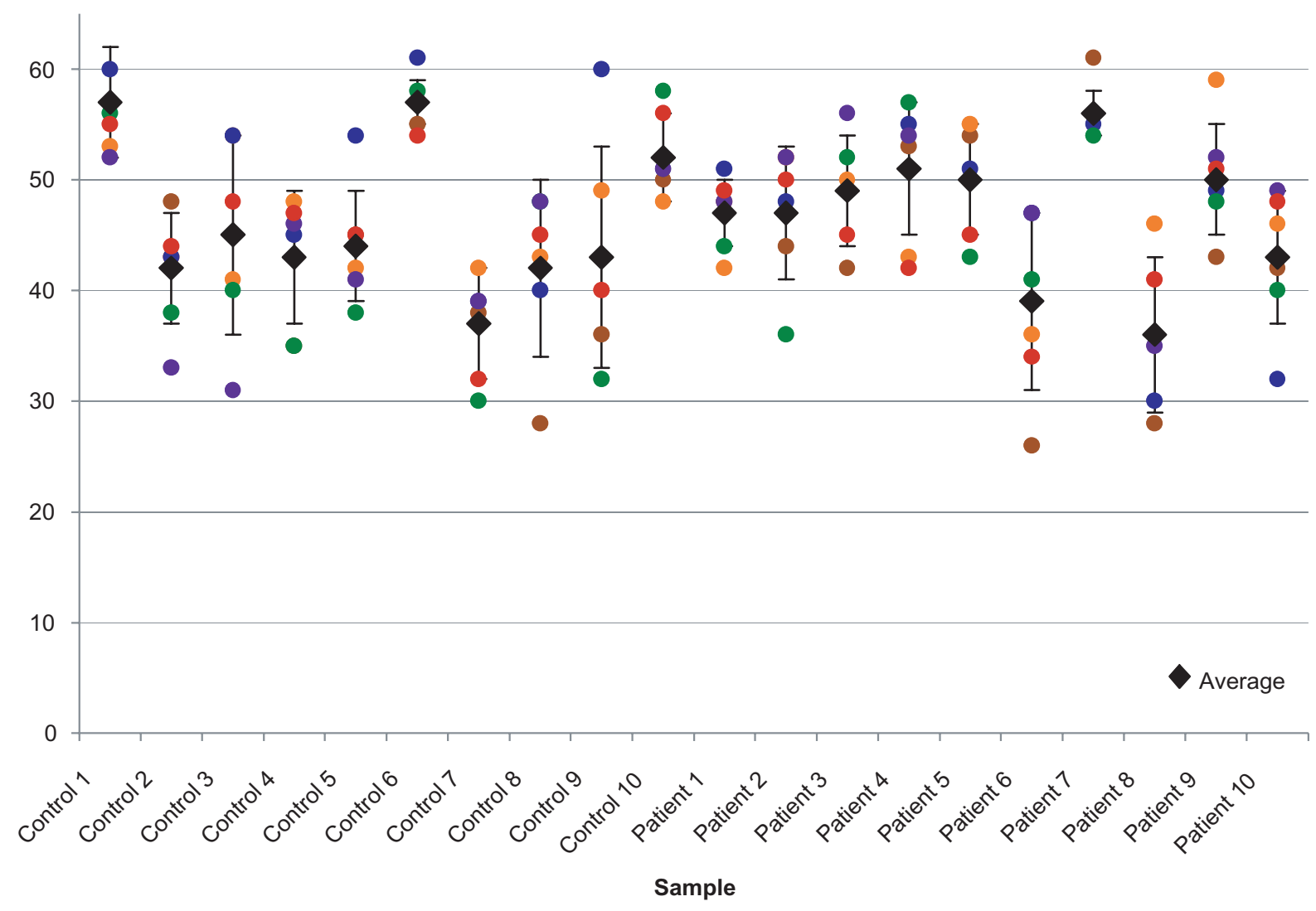

Supplementary Fig. 1. Number of glycan peaks found in the 40\% ACN fractions. Six spectral acquisitions were done for each sample and the relative standard deviations were computed. The RSDs ranged from 3.5\% to $23.3 \%$ and a mean value for $12.6 \%$. Bars for standard deviation of the mean are shown for six replicates. 


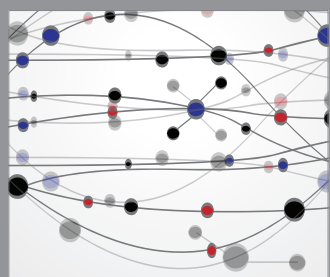

The Scientific World Journal
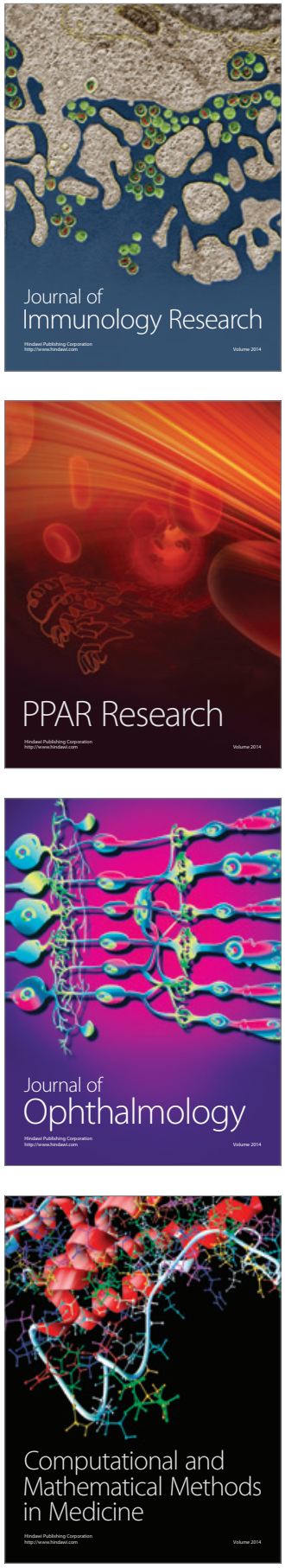

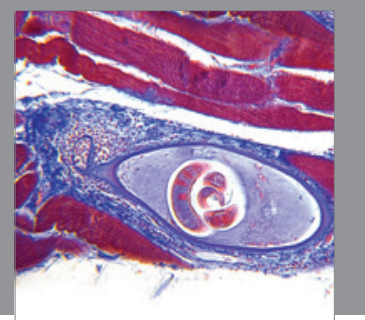

Gastroenterology

Research and Practice
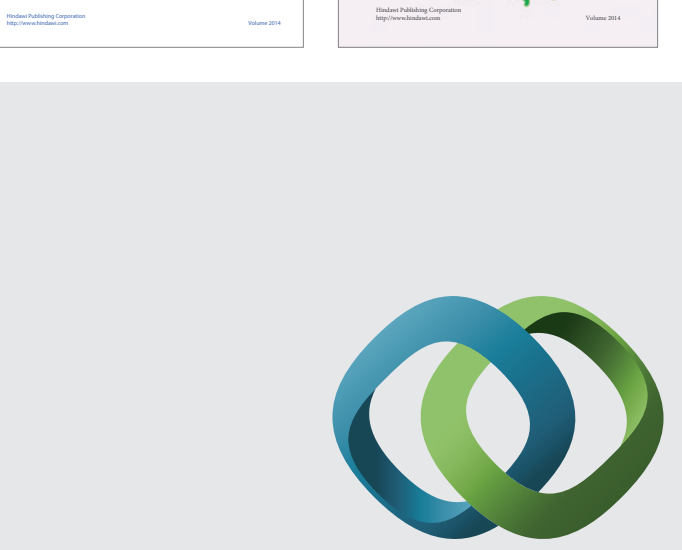

\section{Hindawi}

Submit your manuscripts at

http://www.hindawi.com
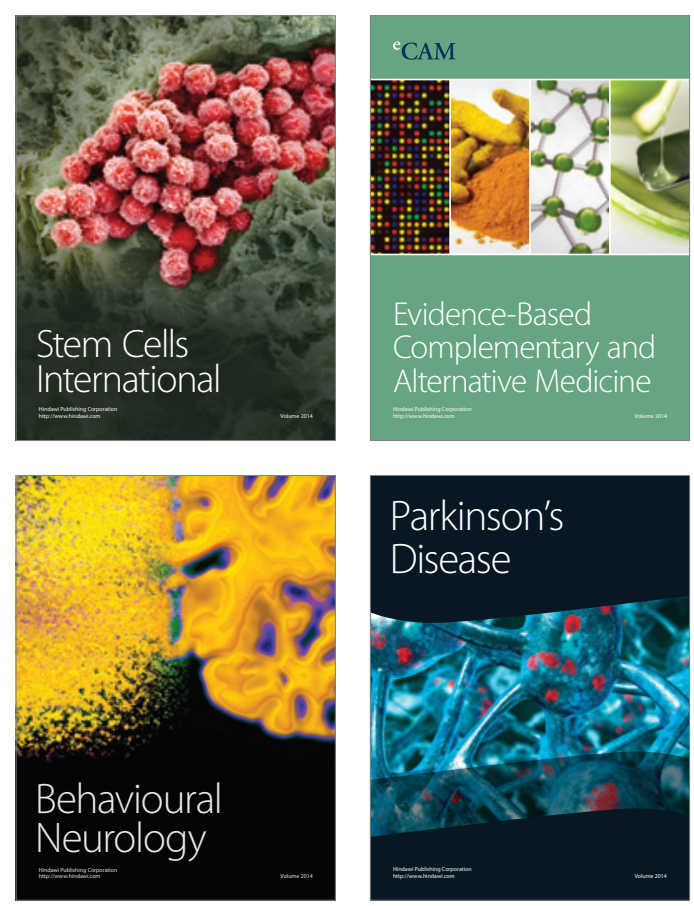

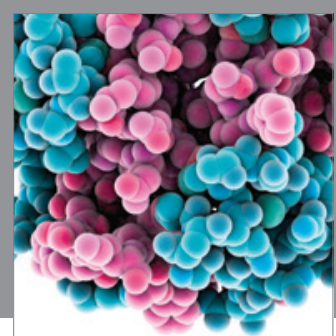

Journal of
Diabetes Research

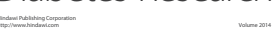

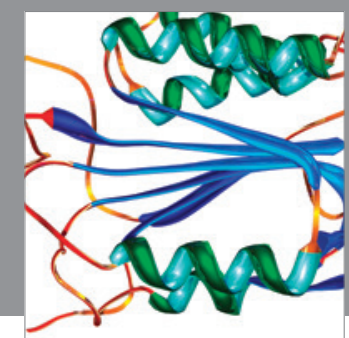

Disease Markers
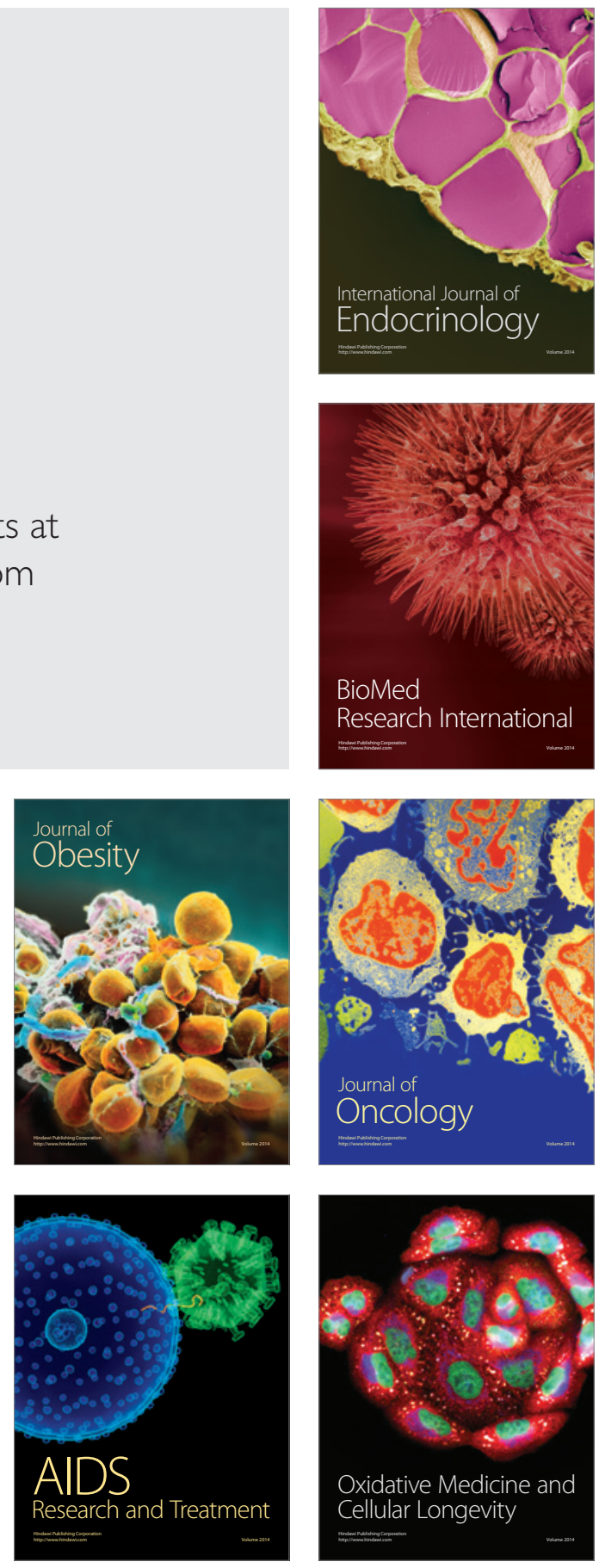